Regular Article

pISSN: 2287-2396, eISSN: 2287-240X

Journal of Forest Science

Vol. 29, No. 3, pp. 194-199, August, 2013

http://dx.doi.org/10.7747/JFS.2013.29.3.194

\title{
Change in Community Composition and Soil Carbon Stock Along Transitional Boundary in a Sub-Tropical Forest of Garhwal Himalaya
}

\author{
Munesh Kumar ${ }^{1, *}$, Manish Kumar ${ }^{1}$, Sajid Saleem ${ }^{1}$, Sunil Prasad ${ }^{1}$ and GS Rajwar ${ }^{2}$ \\ ${ }^{1}$ Department of Forestry and Natural Resources, HNB Garhwal University Srinagar Garhwal, Uttarakhand, India \\ ${ }^{2}$ Department of Botany, Govt. Post Graduate College, Rishikesh 249201, Uttarakhand, India
}

\begin{abstract}
The aim of the present study was to assess the effect of transitional boundary on community composition and soil carbon stock. Five vegetation types were recognized horizontally along the transitional strip based on the dominance of tree species i.e., Pure Anogeissus latifolia forest (P.AL), mixed Pinus roxburghii and Lannea coromandelica forest (M.PR\&LC), pure Pinus roxburghii forest (P.PR), mixed Pinus roxburghii and Lannea coromandelica (M.PR\&LC) and pure Anogeissus latifolia forest (P.AL). The results revealed that Anogeissus latifolia was reported dominant tree in the outer transitional boundaries of the forest, which reduced dominance of trees towards middle where Pinus roxburghii was found dominant. The soil carbon stock was reported higher in the Anogeissus latifolia dominant forest and reduced with the dominance of Pinus roxburghii in the middle site. Both the species are growing close to one another and competing for survival, but the aggressive nature of Anogeissus latifolia particular in this region may change new growth of Pinus roxburghii and will enhance soil carbon stock. But high anthropogenic pressure on Anogeissus latifolia tree species could be limited chance to further its flourish.
\end{abstract}

Key Words: Transitional zone, Pure, mixed, competition, survival

\section{Introduction}

In transition zone more homogenous communities often correspond with sharp environmental and ecological gradients and depicted great influence of dominant plants on ecosystem structure, ecosystem properties and animal communities (Gosz 1993; Risser 1995).

Terrestrial carbon stocks consist of above and below ground carbon. Above ground carbon stock component includes biomass (stems, twigs, leaves, vines, epiphytes and understory) and necromass (dead trunks, standing dead trees and litter in the form of leaves, stem, twigs, flowers, fruits and fire residues). Below ground carbon stock components are roots of live or dead plants, soil organisms and soil organic matter. Carbon stock of a land-use system is influenced by its vegetation. A land use system consisting of tree species with high wood density will have a higher biomass carbon compared to that with a low wood density and similar tree diameter.

In the sub-tropical region of Garhwal Himalaya Anogeissus latifolia and Pinus roxburghii are growing independently as pure forest but overlaps in certain areas which forms a transitional boundary/ecotone zone. In the present field study, a unique feature has been noticed in the

Received: November 14, 2012. Revised: July 25, 2013. Accepted: July 25, 2013. 
transitional boundaries of the forest, where Anogeissus latifolia (Bakli) and Pinus roxburghii (Chir pine) growing closely and forming the transitional boundary. In the transitional boundaries of present study the hypothesis was developed that: (i) Does transitional boundaries affects the community structure and distribution pattern of the species? (ii) Does changing species composition affect soil carbon stock? To test the hypothetical questions, the following objectives were selected; i) Effect of transitional boundaries on community structure and distribution pattern of species and ii) Effect of community structure change on soil carbon stock in transitional boundaries.

\section{Materials and Methods}

\section{Study area}

The study area was located between $30^{\circ} 29^{\prime} \mathrm{N}$ and $78^{\circ} 24^{\prime}$ $\mathrm{E}$ at an elevation ranges from 700-1,000 m mean above sea level. Most of the present study area was situated towards south-west facing aspect with steep slope (Fig. 1, \& Location map) climatic conditions of the area includes cold winters, very hot summers and enough rainfall in rainy seasons.

\section{Vegetation and soil sampling analysis}

A $200 \mathrm{~m}$ wide strip of forest was selected from the base to top along altitudinal gradient covering five different altitudes and each altitude was taken $50 \mathrm{~m}$ apart from each other approximately. The aim of $200 \mathrm{~m}$ wide strip was to cover Anogeissus latifolia, Pinus roxburghii and mixed A. latifolia and $P$ roxburghii forests in the transitional boundary. Five altitudinal strips were choosen along altitudinal gradient on the basis of species dominance i.e., pure Anogeissus latifolia forest (P.AL), mixed Pinus roxburghii and Lannea coromandelica forest (M.PR.LC), pure Pinus roxburghii forest (P.PR), mixed Pinus roxburghii and Lannea coromandelica (M.PR.LC) and pure Anogeissus latifolia forest (P.AL).

Five quadrats (each of 10x10 m size) were used horizontally, from each forest type and repeated for five different altitudes therefore; a total of 25 quadrats were used for the vegetation analysis in entire transitional zone. Every quadrat was placed at $50 \mathrm{~m}$ interval horizontally and vertically both to create uniformity in data collection. Vegetation analysis of tree and shrub layers in each forest site was done on vertical transect, laid across the selected area in fixed interval to avoid biased sampling. Trees were considered to be an

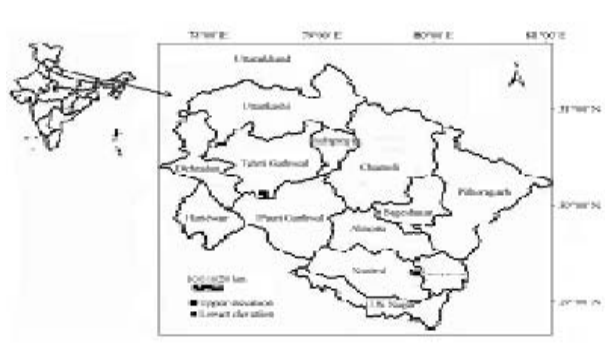

(a)

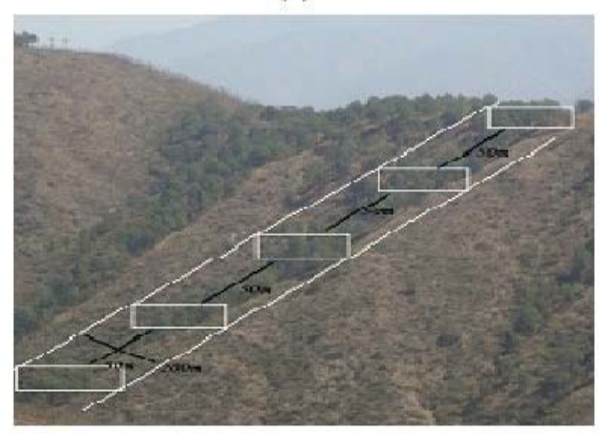

(c)

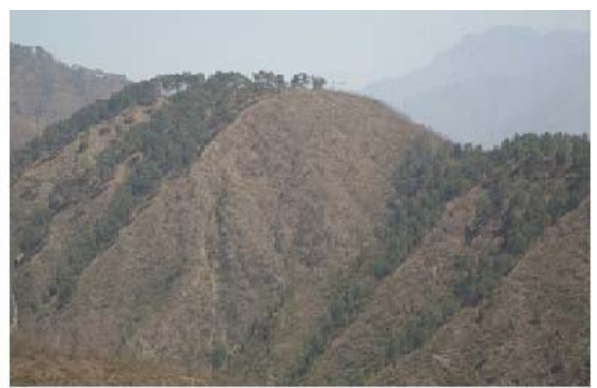

(b)

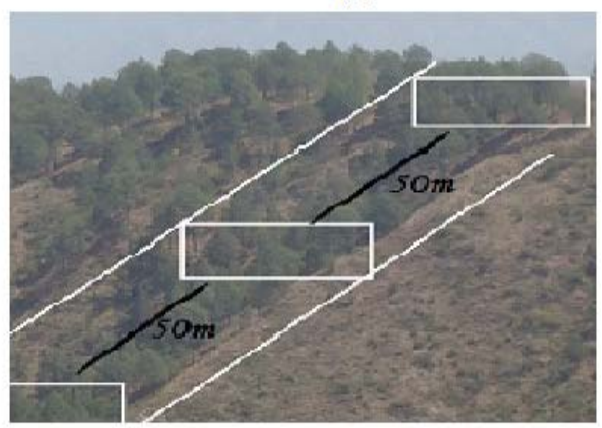

(d)
Fig. 1. Location map (a) and other site conditions (b-d) of the study area. 
individuals $>30 \mathrm{~cm}$ cbh (circumference at breast height). The quantitative informations of vegetation were collected using methods described by Curtis and McIntosh (1950) and importance value index (IVI) as described by Curtis (1959).

The soil samples of each altitudinal strip were collected from $0-30 \mathrm{~cm}$ depth from each quadrat used for vegetation sampling, packed in polythene bags and brought to the laboratory for soil organic carbon analysis. Soil organic carbon was analyzed using methods of Walkley and Black (1934) and soil carbon stock was estimated with the method described by Jha et al. (2003).

\section{Results and Discussion}

\section{Community composition along transition zone}

In P.AL (site-I), A. latifolia was the dominant tree species with highest tree density but highest total basal cover was recorded for Lannea coromandelica. Bauhinia retusa and Terminalia tomentsa were found the associated species on this site. In shrub layer, Carissa opaca was dominant and co-dominanted with Rhus parviflora while associated shrub species in this site were Lantana camara, Murrya koneigii and Legrstroemia parviflora.

In M.PR\&LC (site-II) forest, the dominant tree species was Pinus roxburghii and co-dominanted with Lannea coromandelica. Anogeissus latifolia was the third dominant species on this site. Other associated species recorded on the site were Banhinia retusa, Emblica officinalis and Terminalia tomentosa. In shrub layer, again the aggressive growth was reported in Carissa opaca while Rhus parviflora and Rhus wallichii were associated shrub species.

In P.PR (site-III) forest, the dominant tree species was again Pimus roxburghii with highest values of density and total basal cover and Terminalia tomentosa and Bauhinia retusa were found the associated species. It was interesting to note that Pimus roxburghii increased their dominance towards pure forest and wiped out completely a growth of Anogiesuss laitifola and Lannea coromandelica. Again Carissa opaca was dominant shrub in this forest layer but in the pure forest of Pimus roxburhii has emerged new shrub species of Lanata camara on this site. Other shrubs could not tolerate the canopy cover of the pure Pinus roxburghii site and no species of shrubs were reported. In M.PR\&LC (site IV) forest, the dominant tree was Pinus roxburghii with co-dominant tree L. coromandelica and least dominant tree reported was Emblica officinalis, again the dominance of Pinus roxburghii existed because of more shady conditions. In shrub layer the dominant species was again Carissa opaca with associated species Rhus parviflora, Rhus wallichii and new appeared species Coolobrokia oppositifola and Asparugus racemosa. The appearance of new species on the site could be because of shady conditions on this site.

In the P.AL (site-V) forest again dominant tree was $A$. latifolia with co-dominant species $L$ coromandelica. Other associated trees were Bauhinia retusa and Emblica officinalis. In shrub layer the dominant shrub was Carissa opaca with other associated species i.e., Rhus parviflora, Murrya koenigii, Woodfordia fructicosa and Rhus wallichii.

\section{Soil carbon stock along transitional zone}

The soil carbon stock of P.AL was $69.60 \mathrm{t} \mathrm{ha}^{-1}$ which reduced in M. PR.LC and reported the lowest $49.60 \mathrm{tha}^{-1}$ in the middle zone of P.PR, which was dominated by Pimus roxburghii tree. It again increased in M.PR.LC forest which was $55.60 \mathrm{tha}^{-1}$ and in the P.AL site again the value was highest compared to middle site (Table 1).

Among the forest types, highest tree density $(1,250$ trees/ha) was reported in P.AL (site-I), which reduced towards M.PR\&LC (1,200 trees/ha) and followed by P.PR (Table 2) forest type (820 trees/ha).The reduction in tree density from outer site of transitional zone to middle site might be due to the result of toxic effect produced by Pimus roxburghii which reduced new growth and resulted into lower density of other species. However the density on M.PR\&LC was lowest which represents narrow deep valley where the density of lower girth class trees was lower. But the density again increased in the P.AL forest as compared to M. PR\&LC (site-II) because of higher density values of Bauhinia retusa and Anogeissus Latifolia.

Total basal cover was found lower on both the P.AL forest (site-I and site-V) and this is because of both the transitional boundaries of forests were dominated by Anogeissus latifolia and such forest is under high anthropogenic pressure for the daily demand of the villagers for fodder and other needs. M. PR\&LC and MP\&LC vegetation types have higher total basal cover and it might be due to the mixed type of species composition which could not provide 


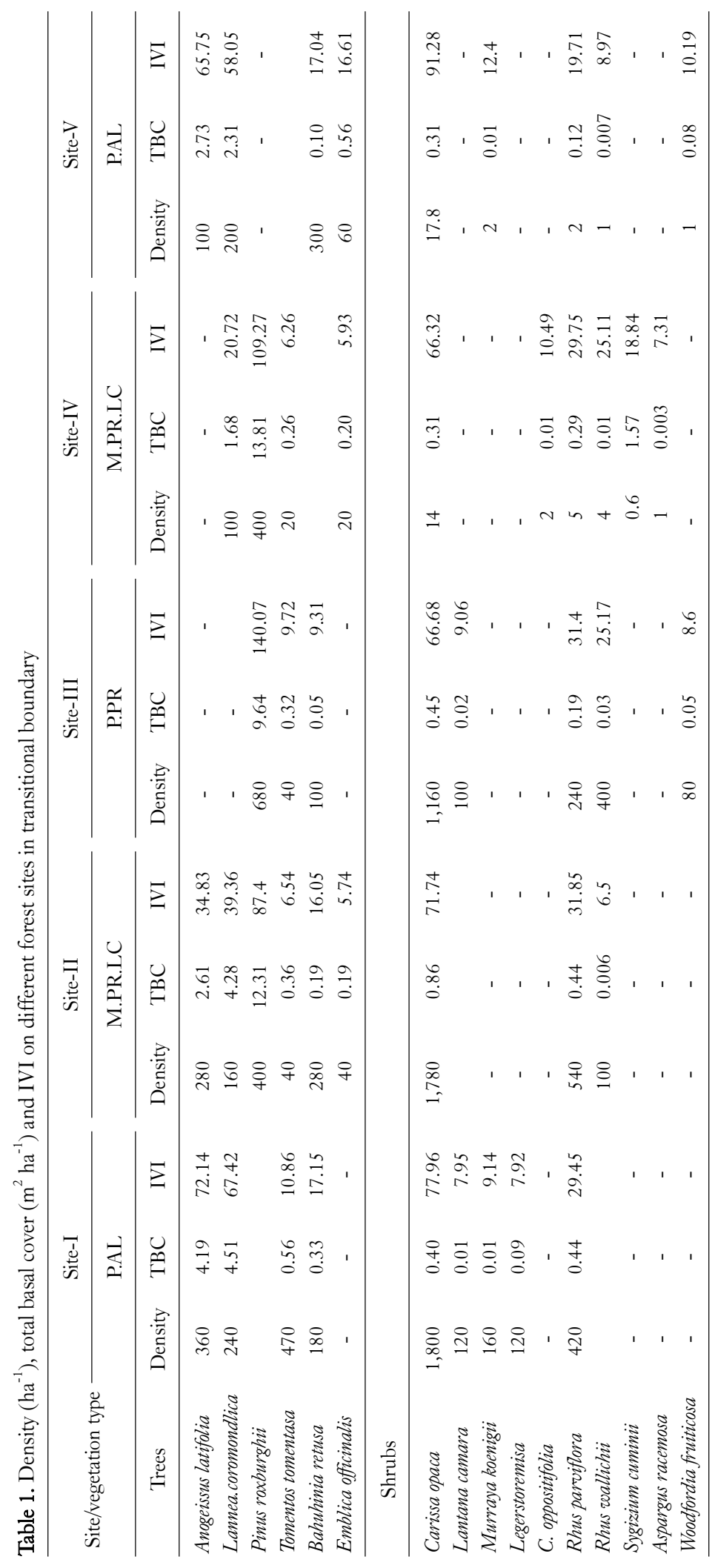


Table 2. Total density and total basal cover on different forest sites in transitional boundary

\begin{tabular}{lccccc}
\hline \multicolumn{1}{c}{ Parameter } & P.AL (Site-I) & M. PR LC (Site-II) & P.PR (Site-III) & M. PR LC Site-IV) & P.AL (Site-V) \\
\hline Total density $\left(\mathrm{tree} \mathrm{ha}^{-1}\right)$ & 1,250 & 1,200 & 820 & 540 & 660 \\
Total TBC $\left(\mathrm{m}^{2} \mathrm{ha}^{-1}\right)$ & 9.59 & 19.94 & 10.01 & 15.95 & 5.7 \\
SOC $\left(\mathrm{g} \mathrm{kg}^{-1}\right)$ & 17.4 & 16.7 & 12.4 & 13.9 & 16.6 \\
Carbon stock $\left(\mathrm{t} \mathrm{ha}^{-1}\right)$ & 69.60 & 66.80 & 49.60 & 55.60 & 66.40 \\
\hline
\end{tabular}

easy accessibility to the villager and time consuming due to mixed species composition.

Between the P.AL forests (site-I and site-V), the higher value of carbon stock was reported in P.AL (site-I) which was $69.60 \mathrm{t} / \mathrm{ha}$ where the density of Anogeissus latifolia was higher. These results indicate that, Anogeissus latifolia species stocks more soil carbon than other recorded species. Similar trends were observed with other sites as soil carbon stock on site-I (P.AL) than on site-II (M.PR\&LC) where density of Anogeissus latifolia was lower than on the site-I and again the carbon stock was lower on site- $V$, where the density was lower compared to site-I and site-II. The soil carbon stock on site-IV and site-III was lower because of non availability of Anogeissus latifolia and higher density of Pinus roxburghii.

Among the sites, the carbon stock of soil reduced form site-I to site-II and site-V to site-IV and lowest on site-III. Thus study suggested that carbon stock of soil increased with reducing presence of Pinus roxburghii and therefore highest value of carbon stock was reported where the Pinus roxburghii was almost absent and higher density of Anogeissus latifolia was recorded.

It has been reported that now-a-days Anogeissus latifolia is dominant on northern aspect with combination of Lannea coromandelica, Emblica officinalis however Pinus roxburghii was dominant on southern aspect few years ago and now moving towards northern aspect and in some places Pinus roxburghii is restricted in the narrow gaze and forming transitional boundary with most of the sites which has already occupied by a Anogiesses latifolia in northwest, northern and eastern aspects.

It is unique to notice that wherever Anogiesses latifolia and Pinus roxburghii were growing closer, most of the areas were occupied by Anogeissus latifolia by replacing Pinus roxburghii. In the present study it has been observed that in the outer boundaries of transition zone, Anogeissus latifolia was dominant and no tree of Pinus roxburghii was reported (site-I and
site-V of P. AL forest). As we move for the vegetation analysis from the transitional boundaries towards the core sites, the density of Pinus roxburghii increased but here the density of Anogeissus latifolia was reduced. Thus the study revealed that both the forests (Pinus roxburghii and Anogeissus latifolia) are surviving intolerably. However, in the mixed site there is severe competition between the species for co-existence. In an earlier study Kumar et al. (2012) carried out a study of the same forest and reported a wider niche for Anogeissus latifolia (1.98) followed by Pinus roxburghii (1.96). Similarly in the present study soil carbon stock was also reported higher in Anogeissus latifolia dominant forest and reduced with the higher densities of Pinus roxburghii. In an earlier study Kumar et al. (2012) reported that soil organic carbon was higher in Anogeissus latifolia and reduced with the mixed forests of Anogeissus latifolia and Pinus roxburghii, both of these forests are still competing for the survival and follow the law of competitive exclusion principle which indicates that between the species competing for the resources in same place cannot co-exist for a longer period and one has to eliminate from the competition in due course of time. Thus the wider niche of Anogeissus latifolia may have chance to occupy the whole resources of Pinus roxburghii forests in future. Although the certain factors may retrieve the condition and also finish the Anogeissus latifolia forest from this area. Kumar et al. (2010) have reported that all the associated tree species of $A$. latifolia forests in this forest are severely lopped by the villagers for various purposes i.e., fuel, fodder, timber etc. However, relative lopping intensity among the species was significantly higher for A. latifolia (45 to $57 \%$ ). Thus lopped whole branches may stop further regeneration of the species.

\section{Conclusions}

The study concluded that if both the species i.e., 
Anogeissus latifolia and Pinus roxburghii follow the law of competitive exclusion principle, one has to eliminate from the transitional boundary and only second will survive. In an earlier study, author revealed a wider niche of Anogeissus latifolia and species might have good chance to occupy the area of Pinus roxburghii in due course of time but it may also retrieve the condition if the high resource pressure remains continued on Anogeissus latifolia and such conditions increase the chances of the replacement of Anogeissus latifolia from the study site.

\section{References}

Curtis JT. 1959. The vegetation of Winconsin. An Ordination of plant communities, University Winconsin Press, Madision Winconsin, pp 657.

Curtis JT, Cottam G. 1956. Plant ecology work book laboratory field reference manual. Burgers publication co., Minnesota, pp
193.

Curtis JT, McIntosh RP. 1950. The Interrelation of certain analytic and synthetic phytosociological characters. Ecology 31: 434-455.

Gosz JR. 1993. Ecotone hierarchies. Ecological Applications 3: 369-376.

Jha MN, Gupta MK, Saxena A, Kumar R. 2003. Kumar Soil organic carbon store in different forests of India. Indian Forester 129: 714-723.

Kumar Munesh, Joshi Mukesh, Todaria NP. 2010. Regeneration status and plant bio-diversity in a sub-tropical forest of Garhwal Himalaya. Journal of Forestry Research 21: 439-444.

Kumar M, Kumar S, Sheikh MA, Gusain MS. 2012. Community structure, species niche width and soil characteristics in a transitional zone of sub-tropical forest. Indian Forester 138: 154-158.

Risser PG. 1995. The status of the science examining ecotones. Bio Science 45: 318-325.

Walkley AE, Black JA. 1934. An examination of the Degtiga Vett. Method for determining soil organic matter and proposed modification of the chromic acid titration method. Soil Science 37: 29. 